\title{
Management of perioperative hypothermia in major surgery: The efficacy of prewarming with Barrier Easy warm blanket and validation of the Spot On thermometry.
}

\author{
Elke Van Gerven, Steve Coppens, Arne Neyrinck
}

Dept. of Anesthesiology, Leuven University Hospital, Leuven, Belgium

\section{BACKGROUND AND GOAL \\ Perioperative hypothermia (core temperature $<36^{\circ} \mathrm{C}$ ) is a common but preventable complication during surgery and is associated with increased risk of infections, bleeding, postoperative shivering and cardiovascular complications. \\ After induction of general anesthesia, the body temperature initially drops due to a redistribution. Previous studies showed that prewarming may be very effective in minimalizing this redistribution hypothermia. \\ Recently a disposable self-warming blanket was developed (Easy warm) with chemical powder that becomes activated in contact with room air $\left(40-42^{\circ} \mathrm{C}\right.$ \\ for 10-12 hours ). In addition, the Spot On thermometry provides a noninvasive temperature assessment (Forehead). \\ The goal of our study was to evaluate the prewarming strategy combining the Easy warm blanket with the Spot On device in patients scheduled for a total esophagectomy.}

\section{MATERIAL AND METHODS}

40 adult patients scheduled for a total esophagectomy under general anesthesia were randomized in two groups. Group 1 (intervention) received the Easy warmer 30 minutes before induction of general anesthesia, and group 2 (control) was covered with normal blankets. Patient core temperature was measured with 2 devices (bladder, Spot On) at regular intervals.

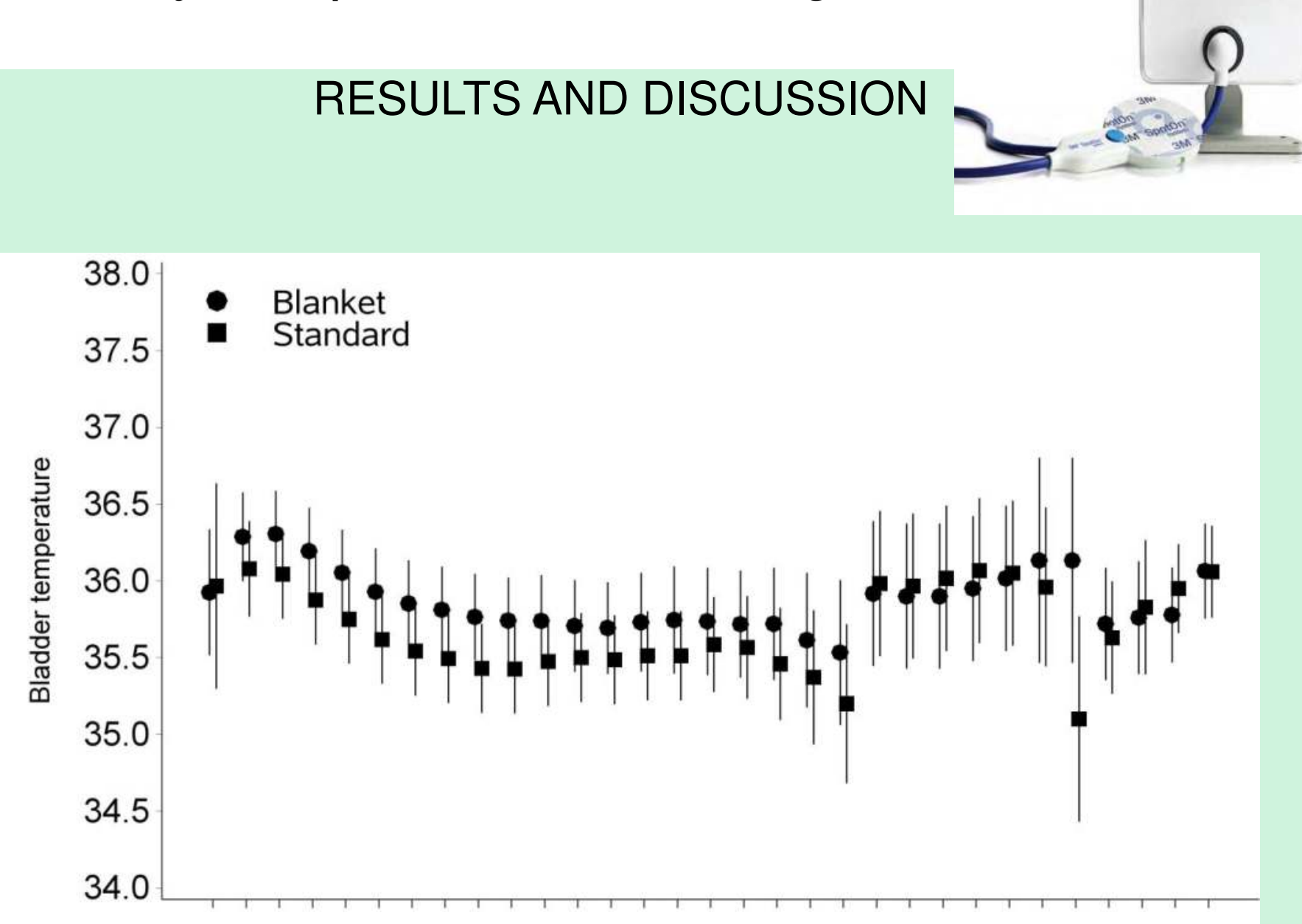

Blanket (N) $\quad 8161717171717171717151515131111111076666666063310101414$ Standard (N) $\quad 3141616161616161616161616161614121077566 \quad 6 \quad 6 \quad 6 \quad 6 \quad 5 \quad 31071615$

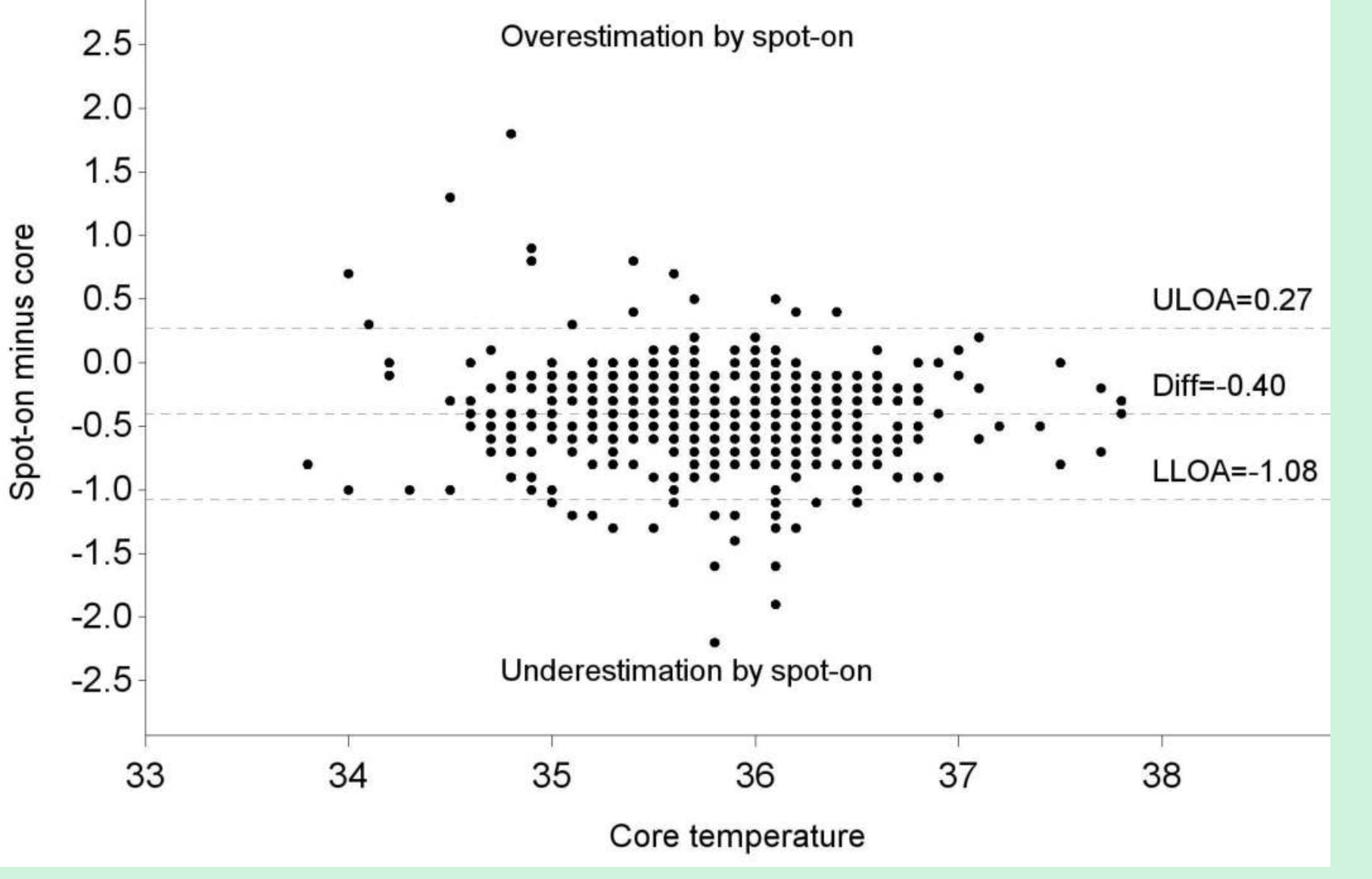

CONCLUSION

A prewarming strategy with the Easy warm did not reduce the incidence of hypothermia. The new Spot On devices was less accurate $\left(-0,4^{\circ} \mathrm{C}\right)$ compared with bladder temperature measurement to access core temperature but as literature points out the use of bladder measurements in hypothermic patient is not the golden standard. Additional research has to be performed to test the accuracy of the non-invasive Spot On device to the core temperature.

\section{REFERENCES}

1. Menzel M, Grote R, Leuchtmann D, Lautenschläger C, Röseler C, Bräuer A. [Implementation of a thermal management concept to prevent perioperative hypothermia Results of a 6-month period in clinical practice]. Anaesthesist. 2016;65(6):423-429. doi:10.1007/s00101-016-0158-3.

2. Sessler DI, Schroeder M, Merrifield B, Matsukawa T, Cheng C. Optimal duration and temperature of prewarming. Anesthesiology. 1995;82(3):674-681.

3. Torossian A, van gerven E, Geertsen K, Horn B, Van de Velde M, Raeder J. Active perioperative patient warming using a self-warming blanket (BARRIER EasyWarm) is superior to passive thermal insulation: a multinational, multicenter, randomized trial. J Clin Anesth. 2016;34:547-554. doi:10.1016/j.jclinane.2016.06.030. 